\title{
Spectroscopic Investigations of Solutions of Lithium bis(fluorosulfonyl)imide (LiFSI) in Valeronitrile
}

\author{
Johannes Neuhaus, Erik von Harbou ${ }^{1}$, Hans Hasse \\ Laboratory of Engineering Thermodynamics (LTD), University of Kaiserslautern, \\ Erwin-Schrödinger Str. 44, D-67663 Kaiserslautern, Germany
}

\begin{abstract}
Lithium bis(fluorosulfonyl)imide (LiFSI) is an interesting electrolyte for lithium ion batteries and valeronitrile is a good solvent for LiFSI as it forms complexes with the $\mathrm{Li}^{+}$-ions. In the present work, this complexation was studied by optical spectroscopy (Raman and IR), as well as by nuclear magnetic resonance (NMR) spectroscopy. Based on the spectroscopic information a chemical model for the complexation was developed and the equilibrium constants for the formation of the different species that were considered are reported.
\end{abstract}

Keywords: NMR, IR, Raman, chemical equilibrium

\section{Introduction}

Lithium bis(fluorosulfonyl)imide (LiFSI) is a promising electrolyte for lithium-ion batteries (LiB). LiFSI has a higher electrical conductivity and has other advantages like a better stability regarding hydrolysis and lower aluminium corrosion, as compared to the benchmark electrolyte $\operatorname{LiPF}_{6}[1,2$,

Email address: erik.vonharbou@mv.uni-kl.de (Hans Hasse) 1 
3, 4, 5, 6, 7, 8].

Aliphatic nitriles, such as acetonitrile, and dinitrile solvents are good solvents for $\mathrm{Li}^{+}$-containing salts, and offer a wide electrochemical window. They are therefore interesting for the application in $\operatorname{LiB}[9,10,11,3,12$, 13, 14, 15, 12, 16]. Acetonitrile is frequently used as an organic solvent for lithium electrolyte benchmarking [10, 11, 3, 9]. However, acetonitrile has a comparatively low normal boiling point, which is undesired in many applications. Therefore, larger $n$-alkyl nitriles, such as $n$-valeronitrile (VN), which was studied here, are also attractive as solvents for $\mathrm{LiB}$ [17].

The reason for the high solubility of $\mathrm{Li}^{+}$-containing salts in nitrile solvents is the formation of coordination complexes of the $\mathrm{Li}^{+}$-ions and the nitrile solvent molecules[18, 9, 10, 19, 11, 3, 12, 20, 21]. These complexes are formed by the coordination of the free electron-pair of the nitrile group nitrogen with the $\mathrm{Li}^{+}$-ion [22, 23]. For solutions in acetonitrile (AN), the coordination complexes of the form $\left[\mathrm{Li}(\mathrm{AN})_{n}\right]^{+}$with a solvation number $n=4$ have been reported in the literature [18, 3]. However, this solvation number only holds for high dilution of the $\mathrm{Li}^{+}$-containing salt and an increasing concentration of the $\mathrm{Li}^{+}$-containing salt decreases the solvation number [3, 21] . Thus, for the description of the complexation in a chemical theory, different coordination complexes (chemical species) of varying stoichiometry $(n \leq 4)$ should be considered.

Han et al. [3] reports quantitative data on the apparent distribution of 
free and coordinated $\mathrm{AN}$ in the system LiFSI + AN. This work, is to our knowledge, the only reference reporting quantitative data on the complexation in a system containing LiFSI in nitrile solvents.

In solutions of LiFSI in VN, the complexation is expected to be similar to that in AN, due to the structural similarity of AN and VN. Still, some differences, due to the long alkyl chain of $\mathrm{VN}$ may be expected. In the present work, the complexation of the $\mathrm{Li}^{+}$-ion with $\mathrm{VN}$ in solutions of LiFSI was investigated with complementary spectroscopic methods: nuclear magnetic resonance (NMR) spectroscopy, as well as optical spectroscopy (Infrared (IR) and Raman). The spectroscopic results are used to develop a chemical model of the complexation.

The results from NMR- and IR spectroscopy were only used for the elucidation of the processes in the solution. Those from Raman spectrocopy were also used for the determination of the equilibrium constants of the formation of the different complexes that were taken into account in the model.

\section{Experimental Section}

\subsection{Chemicals}

Lithium bis(fluorosulfonyl)imide (LiFSI, $\geq 0.999 \mathrm{~g} \mathrm{~g}^{-1}$ ) was supplied by Budan Process UG. $n$-Valeronitrile (VN, $\geq 0.995 \mathrm{~g} \mathrm{~g}^{-1}$ ) was purchased from Sigma Aldrich. All chemicals were used as received. The water content of the pure components was determined by coulometric Karl-Fischer titration 
(Metrohm $831 \mathrm{KF}$ coulometer) and were found to be below $80 \times 10^{-6} \mathrm{~g} \mathrm{~g}^{-1}$ for $n$-valeronitrile, and below $30 \times 10^{-6} \mathrm{~g} \mathrm{~g}^{-1}$ for LiFSI.

All chemicals were handled in an inert gas glove box (GS Glovebox Technik) which maintained an nitrogen atmosphere with a water content of less than $2 \times 10^{-6} \mathrm{~g} \mathrm{~g}^{-1}$. A laboratory balance (Mettler-Toledo AG204) with an accuracy of $\pm 0.0001 \mathrm{~g}$ according to the calibration protocol was used for the gravimetrical sample preparation. The total mass of each prepared sample was larger than $30 \mathrm{~g}$. The samples were sealed in $40 \mathrm{ml}$ glass vials. The uncertainty of the mass fraction of the components is estimated to be $\pm 0.00015 \mathrm{~g} \mathrm{~g}^{-1}$.

Some relevant physico-chemical properties of the studied substances are shown in Tab. 1, wherein $M$ is the molar mass, $T_{\mathrm{nmp}}$ and $T_{\mathrm{nbp}}$ are the normal melting point and the normal boiling point, respectively, $\rho$ is the density, $\eta$ is the shear viscosity, and $\epsilon$ is the dielectric constant.

\subsection{Measurements}

\subsubsection{NMR Spectroscopy}

The measurement of the ${ }^{1} \mathrm{H}-,{ }^{7} \mathrm{Li}-,{ }^{13} \mathrm{C}$ - and ${ }^{19} \mathrm{~F}-\mathrm{NMR}$ chemical shifts in solutions of LiFSI in VN were conducted in a NMR spectrometer with a $9.4 \mathrm{~T}$ vertical superconducting magnet corresponding to a proton Larmor frequency of 400.25 MHz (magnet Ascend 400, console Avance $3 \mathrm{HD}$ 400, Bruker Biospin). The NMR spectrometer was equipped with a probe with cryogenically cooled electronics. The integrated temperature sensor was cal- 
Table 1: Overview of some pure component physico-chemical properties of valeronitrile (VN) and lithium bis(fluorosulfonyl)imide (LiFSI). $M$ is the molar mass, $T_{\text {nmp }}$ and $T_{\text {nbp }}$ are the normal melting point and the normal boiling point, respectively, $\rho$ is the density, $\eta$ is the shear viscosity, and $\epsilon$ is the dielectric constant. The numbers for $\rho, \eta$, and $\epsilon$ for $\mathrm{VN}$ refer to the liquid state at $298.15 \mathrm{~K}$ and ambient pressure. If multiple references are available, the number reported here is the arithmetic mean of these data.

\begin{tabular}{|c|c|c|}
\hline Property & $\mathrm{VN}$ & LiFSI \\
\hline & & 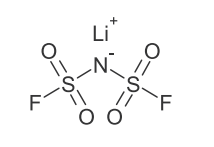 \\
\hline & $\mathrm{C}_{5} \mathrm{H}_{9} \mathrm{~N}$ & $\mathrm{~F}_{2} \mathrm{LiNO}_{4} \mathrm{~S}_{2}$ \\
\hline$M / \mathrm{g} \mathrm{mol}^{-1}$ & 83.13 & 187.1 \\
\hline$T_{\mathrm{nmp}} / \mathrm{K}$ & $176.92[24]$ & $418.2[2]$ \\
\hline$T_{\mathrm{nbp}} / \mathrm{K}$ & $414.28[25,26]$ & \\
\hline$\rho / \mathrm{kg} \mathrm{m}^{-3}$ & $794.80[27,28,29,30]$ & \\
\hline$\eta / \mathrm{mPas}$ & $0.6928[30]$ & \\
\hline$\epsilon$ & $19.87[30,31]$ & \\
\hline
\end{tabular}

ibrated according to the procedure described by Ammann et al. [32]. The uncertainty of the temperature measurement is about $\pm 0.1 \mathrm{~K}$. The measurements were conducted at $298.15 \mathrm{~K}$ and ambient pressure. NMR glass tubes with an outer diameter of $5 \mathrm{~mm}$, which were sealed with a silicon cap, were used. About $0.8 \mathrm{~mL}$ of the pre-mixed homogeneous sample was filled in the NMR glass tube. A fusion-sealed $1.0 \mathrm{~mm}$ glass capillary that was filled with an internal standard was inserted in the sample tube. The internal standard was fluorobenzene $\left(\mathrm{C}_{6} \mathrm{H}_{5} \mathrm{~F}\right)$ for ${ }^{1} \mathrm{H}-,{ }^{13} \mathrm{C}$-, and ${ }^{19} \mathrm{~F}-\mathrm{NMR}$ and an aqueous $\mathrm{LiCl}$ 
solution for ${ }^{7} \mathrm{Li}-\mathrm{NMR}$. Prior to the experiments, the glass tubes were cleaned with water, ethanol, and aceton and dried in an oven at $80^{\circ} \mathrm{C}$.

The NMR spectra were taken with 8 scans for ${ }^{1} \mathrm{H}-\mathrm{NMR}$ and ${ }^{19} \mathrm{~F}-\mathrm{NMR}$ and 16 scans for ${ }^{7} \mathrm{Li}-\mathrm{NMR}$ and ${ }^{13} \mathrm{C}-\mathrm{NMR}$. For the evaluation of the spectra the program Mnova (Mestrelab research) was used.

For all NMR spectra an automatic phase correction and a third-order polynomial baseline correction was performed. The chemical shifts of the internal standard were aligned to compensate small variations in the chemical shifts of the individual samples. Subsequently, the chemical shifts of the investigated nuclei were measured.

\subsubsection{Infrared Spectroscopy}

The infrared spectra were recorded with an attenuated total reflectance Fourier-transform infrared spectrometer (ATR-FTIR; PerkinElmer Spectrum 100 FT-IR, PerkinElmer LAS GmbH). The measurements were conducted at room temperature and ambient pressure. Prior to and between the measurements, the ATR crystal was cleaned with water and acetone. A background scan was performed, which was substracted from the recorded IR spectra. The IR spectra were recorded with a resolution of $4 \mathrm{~cm}^{-1}$ and 8 scans. The observed IR spectra were processed with an automatic baseline correction routine with the program OPUS (Bruker). The $\mathrm{CH}$ vibrations at approx 3000 to $2800 \mathrm{~cm}-1$ was used as internal standard. 


\subsubsection{Raman Spectroscopy}

The Raman spectra were recorded with a Fourier-transform Raman spectrometer equipped with a Nd:YAG laser (1064 nm, $1500 \mathrm{~mW})$ and a Gedetector with liquid nitrogen cooling (Bruker RFS 100-S, Bruker Biospin). The measurements were conducted at room temperature and ambient pressure. The samples were filled into a Pyrex glass Raman tube with optical flats with an outer width of $7 \mathrm{~mm}$ and a height of $50 \mathrm{~mm}$, and sealed with a cap. The sample tube was cleaned with ethanol and aceton. The Raman spectra were recorded with an aperture of $5.0 \mathrm{~mm}$, a laser power of $1300 \mathrm{~mW}$, a resolution of $2 \mathrm{~cm}^{-1}$ and 20 scans. The observed Raman spectra were processed with a automatic baseline correction routine with the program OPUS (Bruker). For the normalization of the Raman spectra, the $\mathrm{CH}$ vibrational band at $2878 \mathrm{~cm}^{-1}$ was used as internal reference. The band does not overlap with any other band. Its intensity is directly proportional to the VN concentration. Peak deconvolution (Lorentzian shape) and integration of the Raman spectra was performed with the program Peaxact 4 (S-Pact).

\section{Data Evaluation, Results and Discussion}

\subsection{NMR Spectroscopy}

Instead of the numbers for the chemical shifts, numbers for chemical shift differences $\Delta \delta$ are presented and discussed in the following. The chemical shift difference is the difference of the chemical shift of the studied peak and a reference peak. The reference was chosen differently in different situations and specified in the text below for each case. 
Figure 1 1 shows chemical shift differences $\Delta \delta$ observed in solutions of LiFSI in $\mathrm{VN}$ as a function of the mole fraction of LiFSI. Results obtained at $298 \mathrm{~K}$ with ${ }^{1} \mathrm{H}-,{ }^{7} \mathrm{Li}-,{ }^{13} \mathrm{C}-$, and ${ }^{19} \mathrm{~F}-\mathrm{NMR}$ spectroscopy are presented in the four panels. The numerical experimental data is presented in the Appendix. ${ }^{1} \mathrm{H}-$ and ${ }^{13} \mathrm{C}-\mathrm{NMR}$ spectroscopy are used for characterizing the solvent $\mathrm{VN} .{ }^{7} \mathrm{Li}-$ NMR spectroscopy is applied for studying the $\mathrm{Li}^{+}$-ion and ${ }^{19} \mathrm{~F}-\mathrm{NMR}$ is used for studying the $\mathrm{FSI}^{-}$-ion. For the different ${ }^{1} \mathrm{H}$ - and ${ }^{13} \mathrm{C}$-solvent peaks, the reference is the corresponding peak in the spectrum of pure VN. For the ions the reference peak is that in solution with the lowest salt concentration that was studied, which is $0.0331 \mathrm{~mol} \mathrm{~mol}^{-1}$.

In principle, the NMR data shown in Figure 1 could be used for quantifying the species distribution in the present system. However, this would require assigning chemical shifts to the different species. The corresponding values of the shifts would have to be adjusted to the experimental data together with the equilibrium constants of the complexation. Preliminary tests showed that, even for simple complexation models, the number of parameters is so high that only ambiguous results are obtained. The efforts were discontinued as the Raman data open a better route for the quantification of the species.

In ${ }^{1} \mathrm{H}-\mathrm{NMR}$, all protons of the alkyl chain show a steady downfield trend (shielding) for increasing mole fraction of LiFSI. In ${ }^{13} \mathrm{C}-\mathrm{NMR}$, the observed trends differ depending on the type of the carbon nucleus. The carbon of the nitrile group exhibits a strong upfield trend (deshielding), while the carbons 

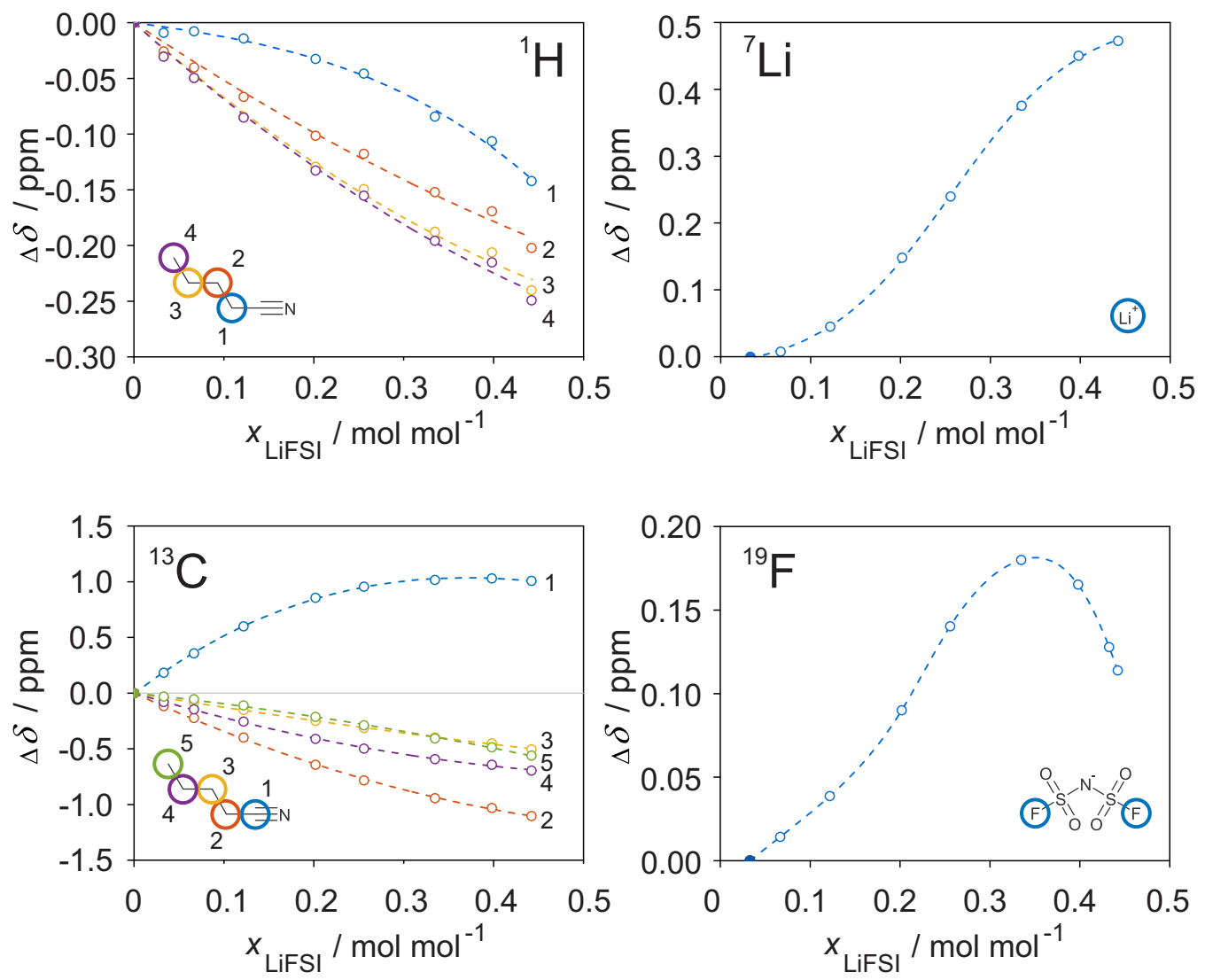

Figure 1: Chemical shift differences $\Delta \delta=\delta_{\text {peak }}-\delta_{\text {reference }}$ in solutions of LiFSI in VN at $298 \mathrm{~K}$. The studied peaks are indicated by colored circles in the structural formulas. The reference is indicated by a full symbol in all cases. 
of the alkyl chain exhibit a downfield trend (shielding) for increasing mole fraction of LiFSI.

In ${ }^{7} \mathrm{Li}-\mathrm{NMR}$, the $\mathrm{Li}^{+}$-ion peak shows a s-shaped upfield trend for increasing mole fraction of LiFSI. In ${ }^{19} \mathrm{~F}-\mathrm{NMR}$, the peak of the fluorine nuclei of the $\mathrm{FSI}^{-}$-ion shows an upfield trend (deshielding) for increasing mole fractions of LiFSI with a maximum at about $0.33 \mathrm{~mol} \mathrm{~mol}^{-1}$ and a downfield trend (shielding) beyond this point.

The findings from ${ }^{1} \mathrm{H}$ - and ${ }^{13} \mathrm{C}-\mathrm{NMR}$ yield the following picture of the VN molecules in the studied solutions. The strong deshielding of the carbon of the nitrile group is attributed to the formation of the ion-dipol coordination between the $\mathrm{Li}^{+}$-ion and the free electron pair of the nitrile nitrogen. The ion-dipole coordination significantly transfers electrons towards the nitrogen of the nitrile group and thus, decreases the electron density of the nitrile carbon. The decrease of electron density of the nitrile carbon, results in a lengthening of the $\mathrm{C}_{1}-\mathrm{C}_{2}$ bond. By lengthening the $\mathrm{C}_{1}-\mathrm{C}_{2}$ bond, the $\mathrm{C}-\mathrm{H}$ and $\mathrm{C}-\mathrm{C}$ bond lengths in the alkyl chain become shorter. This results in an increase of the electron density (shielding) in the vicinity of the individual proton and carbon nuclei of the alkyl chain. Further proofs of this hypothesis are given in the following sections, cf. Sections 3.2 and 3.3 as well as the Supporting Information.

The upfield trend (deshielding) in the relative chemical shift of the $\mathrm{Li}^{+}$-ion peak $\left({ }^{7} \mathrm{Li}-\mathrm{NMR}\right)$ can be attributed to the fact that the number of coordinated 
nitrile molecules in the first solvation shell of the $\mathrm{Li}^{+}$-ions decreases with increasing LiFSI concentration. The flattening of the upfield trend for mole fractions of LiFSI higher than $0.33 \mathrm{~mol} \mathrm{~mol}^{-1}$ indicates that the reduction in the number of coordinated nitrile molecules either becomes less important or that it is compensated by some other effect. Such a compensation might result from the association of the $\mathrm{Li}^{+}$-ions and its counter-ion $\mathrm{FSI}^{-}$, i.e. the beginning formation of ion-pairs. With increasing LiFSI concentration the fluorine nuclei are deshielded first. This is presently not fully understood, but might be a result of the different charge distribution of the cis- and trans-conformers of the $\mathrm{FSI}^{-}$-ion [33, 34, 35, 36]. The beginning formation of ion-pairs then leads to a reversing of that trend. This interpretation would also explain the maximum of the curve in the results from ${ }^{19} \mathrm{~F}-\mathrm{NMR}$ spectroscopy, shown in Figure 1.

\subsection{Infrared Spectroscopy}

Figure 2 shows IR spectra of solutions of LiFSI in VN at room temperature for different molar ratios of VN / LiFSI. Only the region of 2200 to $2325 \mathrm{~cm}^{-1}$ is shown in which the bands result from the $\mathrm{C} \equiv \mathrm{N}$ stretching vibration. Two bands are observed which can be assigned to the uncoordinated VN (Band A at $2246 \mathrm{~cm}^{-1}$ ) and the coordinated VN (Band B at $2276 \mathrm{~cm}^{-1}$ ). Coordination of nitriles is known to lead to a blue shift of the $\mathrm{C} \equiv \mathrm{N}$ stretching

vibrational band [22, 23]. As the LiFSI concentration increases, the size of Band A decreases and that of Band B increases, i.e. a larger fraction of the $\mathrm{VN}$ is coordinated, as expected. An isosbestic point is found at $2262 \mathrm{~cm}^{-1}$. For high mole fractions of LiFSI $\left(0.33 \mathrm{~mol} \mathrm{~mol}^{-1}\right)$, a deviation from that isos- 


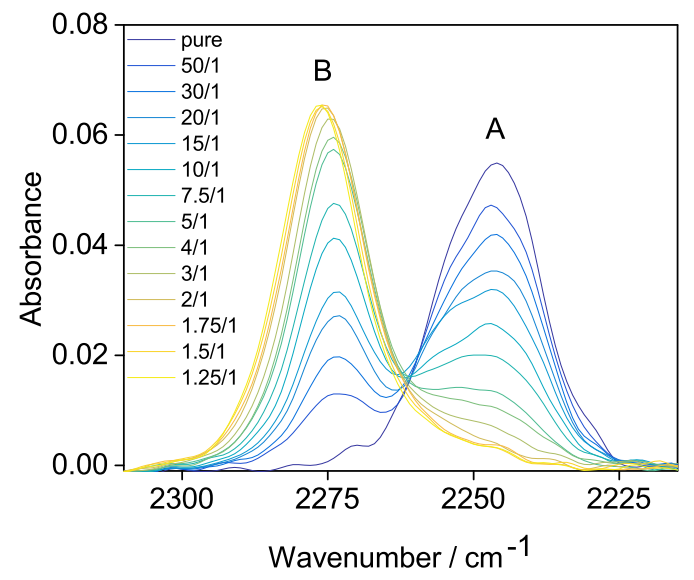

Figure 2: Normalized IR spectra of solutions of LiFSI in VN room temperature: results for different molar ratios of VN / LiFSI. Only the spectral region of the bands of the $\mathrm{C} \equiv \mathrm{N}$ stretching vibration is shown.

bestic point is observed, which is a consequence of the fact that the Band B is not only one distinct species, but complexes of different stoichiometry. The coordination number of these complexes obviously affects the $\mathrm{C} \equiv \mathrm{N}$ vibration.

Additional results from the IR spectroscopic studies are presented in the Appendix. There, results for the spectral regions with the bands of the $\mathrm{C}-\mathrm{C}$ and $\mathrm{C}-\mathrm{H}$ stretching vibrations and the bands of the vibrational modes in the $\mathrm{FSI}^{-}$-ion are shown for solutions with different VN / LiFSI ratios. They give further evidence for the coordination and insight into its consequences on the structure of VN.

Preliminary tests were carried out to evaluate the data shown in Figure 2 using Lambert-Beer's law in order to obtain quantitative information on the 
species distribution, or at least the mole fraction of the free VN. Unfortunately, the extinction coefficients of the $\mathrm{C} \equiv \mathrm{N}$ stretching vibrational band depend strongly on the coordination state and are difficult to determine. The quantitative evaluation is hindered further by the fact that Band B results from different species which cannot be resolved. The efforts to evaluate the IR data quantitatively were not pursued as the Raman spectra turned out to be suited better for the quantification of the species in the present system.

\subsection{Raman Spectroscopy}

Figure 3 shows the normalized Raman spectra of solutions of LiFSI in VN with different molar ratios of VN / LiFSI at room temperature. Only the region is shown in which the bands from the stretching vibration of the nitrile group $(\mathrm{C} \equiv \mathrm{N})$ in $\mathrm{VN}$ appear $\left(2225\right.$ to $2350 \mathrm{~cm}^{-1}$ ). As expected, the results are similar to those obtained with IR spectroscopy. There are bands which can be assigned to the uncoordinated VN (Band A at $2246 \mathrm{~cm}^{-1}$ ) [37, 38, 39] and the coordinated VN (the overlapping Bands B1 and B2 at 2276 to $2281 \mathrm{~cm}^{-1}$ ) [23, 40]. The blue shift of the $\mathrm{C} \equiv \mathrm{N}$ vibrational band that is observed upon coordination originates from hyperconjugation [41, 42, 43, 44]. As the LiFSI concentration increases, the size of Band A decreases and that of the Bands B1 and B2 increases, i.e. a larger fraction of the VN is coordinated. Band B2 is hardly discernible at low LiFSI concentrations but becomes important in concentrated solutions. There is an isosbestic point at about $2262 \mathrm{~cm}^{-1}$, which, however, is smeared out at high LiFSI concentrations. 


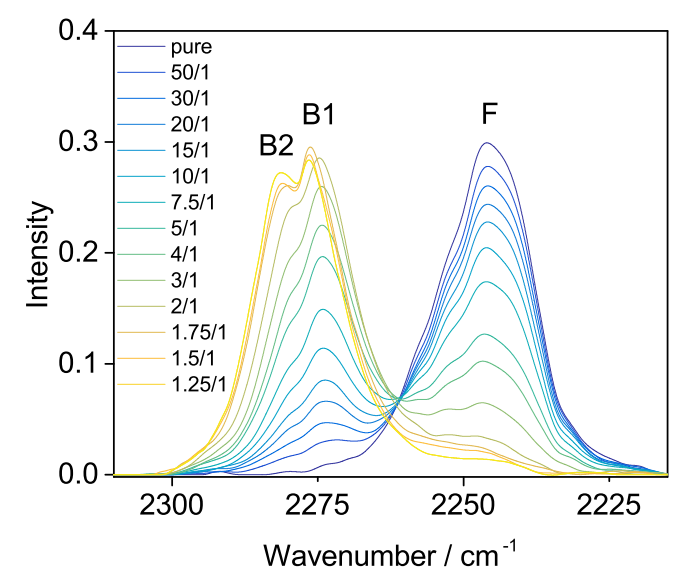

Figure 3: Normalized Raman spectra of solutions of LiFSI in VN at room temperature: results for different molar ratios of VN / LiFSI. Only the spectral region of the bands of the $\mathrm{C} \equiv \mathrm{N}$ stretching vibration is shown. Three bands were assigned for the quantification: F free VN and B1, B2 coordinated VN.

The Raman scattering coefficients of the $\mathrm{C} \equiv \mathrm{N}$ bond vibration are known to depend only weakly on the coordination [23, 40]. This is in contrast to the behavior of the extinction coefficients in IR spectroscopy, as discussed above. Therefore, Raman spectroscopy is the preferred method to obtain quantitative information on the speciation in the studied mixtures.

The three bands in the Raman spectra shown in Figure 3 were evaluated quantitatively. The peak deconvolution was carried out by representing the spectrum by three overlapping Lorentzian peak that correspond to the three bands and determining their scattering coefficients by a fit. From the integration of these peaks the normalized integrated intensities of the bands $I_{\mathrm{F}}$, $I_{\mathrm{B} 1}$, and $I_{\mathrm{B} 2}$ were obtained. The numerical results are given in the Support- 
ing Information. Their summation of the intensity of the three bands yields the total intensity $I_{\mathrm{T}}$ :

$$
I_{\mathrm{T}}=I_{\mathrm{F}}+I_{\mathrm{B} 1}+I_{\mathrm{B} 2}
$$

Furthermore, the molality of $\mathrm{VN}$ in the solution $\left(m_{\mathrm{T}}\right.$, where $\mathrm{T}$ stands for total) is known, which is related to the molalities of the true species by:

$$
m_{\mathrm{T}}=m_{\mathrm{F}}+m_{\mathrm{B} 1}+m_{\mathrm{B} 2}
$$

Molalities are defined here referring to $1000 \mathrm{~g}$ of $\mathrm{VN}$, independent of the form in which $\mathrm{VN}$ is present. The intensities $I_{i}$ and the molalities $m_{i}$ are linked by the scattering coefficients $J_{i}$ :

$$
I_{i}=J_{i} m_{i} \quad \text { with } \quad(i=\mathrm{F}, \mathrm{B} 1, \mathrm{~B} 2)
$$

It follows from Equations (1) to (3) that the following equation holds:

$$
I_{\mathrm{T}}=J_{\mathrm{F}} m_{\mathrm{T}}+\left(1-\frac{J_{\mathrm{F}}}{J_{\mathrm{B} 1}}\right) I_{\mathrm{B} 1}+\left(1-\frac{J_{\mathrm{F}}}{J_{\mathrm{B} 2}}\right) I_{\mathrm{B} 2}
$$

This equation must be fulfilled for each experiment (here: 14 experiments with different ratios VN / LiFSI, cf. Figure 3). It is assumed here that the scattering coefficients are constant. The three scattering coefficients $J_{\mathrm{F}}, J_{\mathrm{B} 1}$, and $J_{\mathrm{B} 2}$ are determined from the data in such a way as to obtain the best fit for $I_{\mathrm{T}}\left(I_{\mathrm{B} 1}, I_{\mathrm{B} 2}\right)$ by eq (44) for the entire experimental data set. Good agreement is observed. The resulting scattering coefficients are: $J_{\mathrm{F}}=$ $1.0112 \mathrm{~cm}^{-1} \mathrm{~mol}^{-1} \mathrm{~kg}, J_{\mathrm{B} 1}=1.1161 \mathrm{~cm}^{-1} \mathrm{~mol}^{-1} \mathrm{~kg}, J_{\mathrm{B} 2}=1.4015 \mathrm{~cm}^{-1} \mathrm{~mol}^{-1} \mathrm{~kg}$. Figure 4 shows the result in a plot in which the experimental data points and the results from the correlation are compared. Good agreement is observed. From the scattering coefficients and the intensities, the concentrations of free 


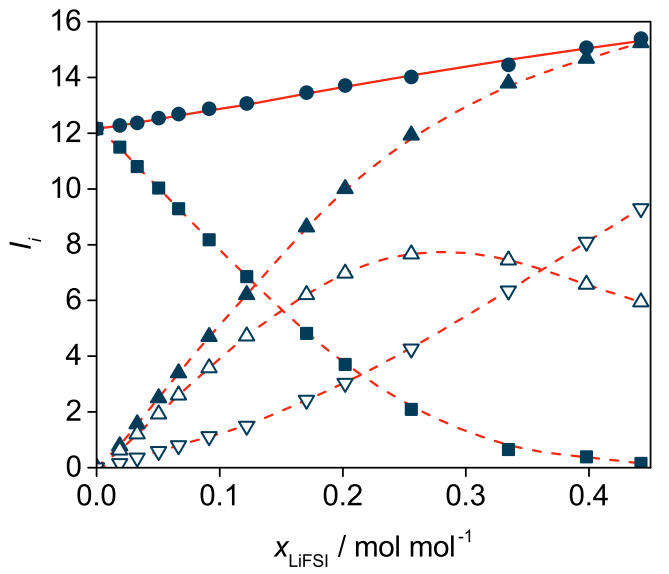

Figure 4: Normalized integrated Raman intensities of the nitrile group $(\mathrm{C} \equiv N)$ as a function of the mole fraction of LiFSI at room temperature and ambient pressure. The symbols indicate the normalized integrated intensity of free $\left(I_{\mathrm{F}}\right.$ : full squares) and coordinated VN ( $I_{\mathrm{B}_{1}}$ : triangles up, $I_{\mathrm{B}_{2}}$ : triangles down, and $I_{\mathrm{B}}\left(=I_{\mathrm{B}_{1}}+I_{\mathrm{B}_{2}}\right)$ : full triangles), respectively, and the normalized total integrated intensity $\left(I_{\mathrm{T}}\right.$, full circles). The lines indicate the fit of the normalized integrated intensities according to eq (4), total (solid) and free/bound (dashed).

and coordinated VN can be calculated using eq (3). The results are presented in Figure 6, panel a). Numerical results are given in Table 2 on the mole fraction basis. The differentiation of B1 and B2 was only necessary for the data evaluation. B1 and B2 could not be assigned to species, thus, in the following only the sum of B1 and B2 is discussed.

The Raman spectrocopic data give also quantitative information on the coordination number $n$ in the complexes $\left[\mathrm{Li}(\mathrm{VN})_{n}\right]^{+}$, which can be calculated 
from:

$$
n=\frac{m_{\mathrm{Li}^{+}}}{\left(m_{\mathrm{T}}-m_{\mathrm{F}}\right)}
$$

where $m_{\mathrm{Li}^{+}}$is the molality of $\mathrm{Li}^{+}, m_{\mathrm{T}}$ is the molality of $\mathrm{VN}$, and $m_{\mathrm{F}}$ is the molality of the free VN. It is assumed here that LiFSI is fully dissociated such that $m_{\mathrm{Li}^{+}}=m_{\mathrm{LiFSI}}$. The results are presented in Figure 5 in which the coordination number $n$ is shown as a function of $x_{\text {LiFSI }}$ as determined for the present Raman experiments at room temperature. A linear decrease of $n$ is observed. The extrapolation clearly indicates that at infinite dilution of LiFSI four VN are coordinated to $\mathrm{Li}^{+}$. In Figure 5 only the data for $x_{\mathrm{LiFSI}}>$ $0.1 \mathrm{~mol} \mathrm{~mol}^{-1}$ are shown as for more diluted solutions the determination of $n$ from eq (5) is subject to large uncertainties. This stoichiometric ratio is in good agreement with literature data on $\mathrm{Li}^{+}-n$-alkyl nitrile complexes [45, 3].

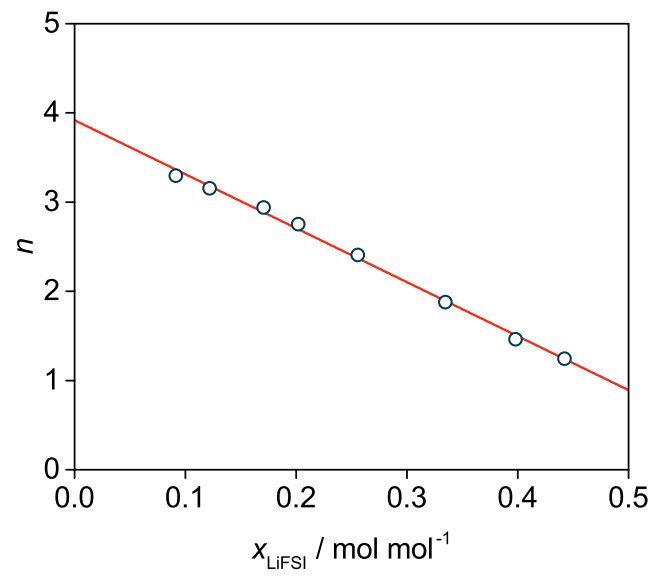

Figure 5: Coordination number $n$ in the $\left[\mathrm{Li}(\mathrm{VN})_{n}\right]^{+}$complexes in solutions of LiFSI in VN at room temperature. Results from Raman spectroscopic investigations. Experimental data are shown together with a linear fit. 
Table 2: Quantitative data on the speciation in solutions of LiFSI in VN at room temperature determined by Raman spectrocopy.

\begin{tabular}{cc}
\hline \hline$x_{\mathrm{LiFSI}} / \mathrm{mol} \mathrm{mol}^{-1}$ & $x_{\mathrm{VN}, \mathrm{F}} / \mathrm{mol} \mathrm{mol}^{-1}$ \\
\hline 0.0000 & 1.0000 \\
0.0189 & 0.9267 \\
0.0331 & 0.8595 \\
0.0505 & 0.7814 \\
0.0667 & 0.7095 \\
0.0914 & 0.6074 \\
0.1219 & 0.4934 \\
0.1706 & 0.3279 \\
0.2019 & 0.2421 \\
0.2557 & 0.1288 \\
0.3347 & 0.0364 \\
0.3980 & 0.0194 \\
0.4422 & 0.0069 \\
\hline$u\left(x_{\mathrm{LiFSI}}\right)=0.0002 \mathrm{~mol} \mathrm{~mol}$ \\
\hline \hline
\end{tabular}


Table 3: Numerical data of the mean $\mathrm{Li}^{+}$-ion solvation number $n$ calculated with eq (5) and concentrations from Table 2

\begin{tabular}{cc}
\hline \hline$x_{\text {LiFSI }} / \mathrm{mol} \mathrm{mol}^{-1}$ & $n$ \\
\hline 0.0914 & 3.30 \\
0.1219 & 3.16 \\
0.1706 & 2.94 \\
0.2019 & 2.75 \\
0.2557 & 2.41 \\
0.3347 & 1.88 \\
0.3980 & 1.46 \\
0.4422 & 1.25 \\
\hline$u\left(x_{\text {LiFSI }}\right)=0.0002 \mathrm{~mol} \mathrm{~mol}^{-1}$ \\
\hline \hline
\end{tabular}




\subsection{Chemical Model of Complexation}

The complexation of $\mathrm{Li}^{+}$and $\mathrm{VN}$ is described here by a chemical model. It is based on the Raman spectroscopic results from the present work, but the results are also in line with the evidence from the present NMR and IR spectroscopic investigations.

As shown in Figure 5, the Raman spectroscopic data indicate that the maximum coordination number in $\left[\mathrm{Li}(\mathrm{VN})_{n}\right]^{+}$is $n=4$ and that the coordination number decreases strongly with increasing LiFSI concentration. Hence, four complexes with $n=(1,2,3,4)$ are considered in the model. Their formation is described by chemical equilibria:

$$
\begin{gathered}
\mathrm{Li}^{+}+\mathrm{VN} \rightleftharpoons\left[\mathrm{Li}(\mathrm{VN})_{1}\right]^{+} \\
{\left[\mathrm{Li}(\mathrm{VN})_{1}\right]^{+}+\mathrm{VN} \rightleftharpoons\left[\mathrm{Li}(\mathrm{VN})_{2}\right]^{+}} \\
{\left[\mathrm{Li}(\mathrm{VN})_{2}\right]^{+}+\mathrm{VN} \rightleftharpoons\left[\mathrm{Li}(\mathrm{VN})_{3}\right]^{+}} \\
{\left[\mathrm{Li}(\mathrm{VN})_{3}\right]^{+}+\mathrm{VN} \rightleftharpoons\left[\mathrm{Li}(\mathrm{VN})_{4}\right]^{+}}
\end{gathered}
$$

A complexation of the $\mathrm{FSI}^{-}$-ion is not considered as it is known to interact only weakly with VN [2]. Also the formation of ion-pairs is not accounted for, even though they may play a role at the highest concentrations of LiFSI that were studied in the present work, see Section 3.1. Hence, it is assumed that LiFSI is always fully dissociated. Preliminary tests with models that account for the formation of ion pairs did not show a significant improvement 
of the fit. It was therefore decided not to include them in the model.

Mole fraction based equilibrium constants are used here for describing the equilibria of the Reactions [ to IV.

$$
K_{x}=\prod_{i=1}^{N_{c}} x_{i}^{\nu_{i}}
$$

where $x_{i}$ is the true mole fraction of component $i$ and $\nu_{i}$ is the stoichiometric factor. For the reaction products, the algebraic sign of $\nu_{i}$ is positive and for educts, it is negative. It was out of the scope of the present study to develop an activity-based model.

The present experimental Raman data does not provide sufficient information to determine the four equilibrium constants $K_{x, \mathrm{I}}, K_{x, \mathrm{II}}, K_{x, \mathrm{III}}$, and $K_{x, \text { IV }}$ in a meaningful way without using further simplifying assumptions. Preliminary tests showed that the following assumption gave good results:

$$
\alpha=\frac{K_{x, \mathrm{II}}}{K_{x, \mathrm{I}}}=\frac{K_{x, \mathrm{III}}}{K_{x, \mathrm{II}}}=\frac{K_{x, \mathrm{IV}}}{K_{x, \mathrm{III}}}
$$

This assumption reduces the number of adjustable parameters in the model to two, for which $K_{x, \mathrm{I}}$ and $\alpha$ were chosen.

$K_{x, \mathrm{I}}$ and $\alpha$ were determined from a fit of the experimental data for the fraction of the VN that is bound in complexes of any form. The sum of the squared relative deviations between the experimental data and the model was employed as objective function. The optimization was carried out in Mathworks Matlab 2016b using the solver lsqnonlin. The resulting numbers for $K_{x, \mathrm{I}}$ and $\alpha$ are reported in Table 4, which, for completeness, also 
contains the numbers for $K_{x, \mathrm{II}-\mathrm{VI}}$.

Figure 6] shows the results of the fit. The two panels show different properties of the LiFSI solutions in $\mathrm{VN}$ at room temperature as a function of the apparent mole fraction of LiFSI. Figure 6 a) shows the model results for the apparent mole fraction of VN that is present in uncoordinated (free) and coordinated form is shown and in Figure 6 b) depicts the true mole fractions of the different species in the solutions. Figure 6 a) contains also the experimental results for comparison.

Figure 6]a) shows that the model describes the distribution of VN between the uncoordinated and the coordinated form well. For increasing mole fraction of LiFSI the fraction of free VN molecules drops sharply and is almost zero for the highest studied LiFSI concentrations. Figure 6 b) shows that in diluted solution of LiFSI in VN the complexes $\left[\mathrm{Li}(\mathrm{VN})_{4}\right]^{+}$prevail, whereas with increasing LiFSI concentration, successively $\left[\mathrm{Li}(\mathrm{VN})_{3}\right]^{+},\left[\mathrm{Li}(\mathrm{VN})_{2}\right]^{+}$, and finally $\left[\mathrm{Li}(\mathrm{VN})_{1}\right]^{+}$become important.

The present model can be applied also to describe the NMR- and the IR-data collected in the present work quantitatively. However, to this end, a large number of parameters has to be estimated by means of the few experimental data that are available. For the description of the NMR results, chemical shifts of nuclei in the different complexes have to be fitted to the data. Similarly, for the evaluation of the IR bands, the extinction coefficients for the different complexes have to be fitted. Preliminary tests showed that 
good descriptions of both the NMR and the IR data are achievable, but due to the large number of parameters, the fit is ambiguous and gives no additional insight. Therefore, these tests are not discussed further here.
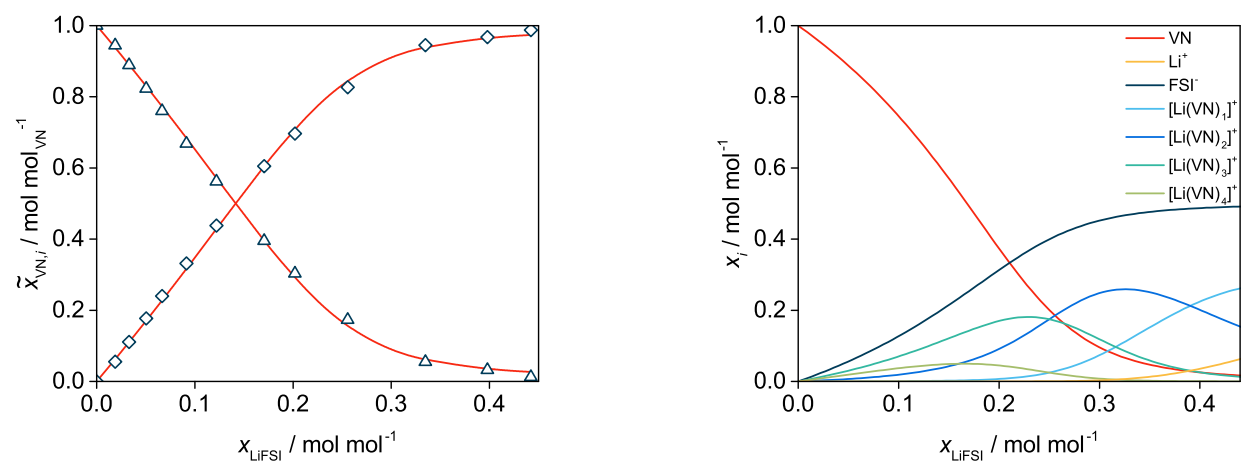

Figure 6: Panel a): Apparent mole fractions of free (triangle) and coordinated (diamonds) VN molecules. Symbols: experimental data (cf. Table 2). Lines: model. Panel b): Species distribution in the liquid phase. Both, as a function of the mole fraction of LiFSI at room temperature and ambient pressure.

Table 4: Mole-fraction based chemical constants of the complexation of $\mathrm{VN}$ and $\mathrm{Li}^{+}$at room temperature, cf. Reactions \to IV The $\alpha$ parameter is 0.142 .

\begin{tabular}{cccc}
\hline \hline$K_{x, \mathrm{I}}$ & $K_{x, \mathrm{II}}$ & $K_{x, \mathrm{III}}$ & $K_{x, \mathrm{IV}}$ \\
\hline 247.24 & 35.11 & 4.99 & 0.71 \\
\hline \hline
\end{tabular}

\section{Conclusions}

In the present work, solutions of LiFSI $+n$-valeronitrile $(\mathrm{VN})$ were investigated with different spectroscopic methods, namely: nuclear magnetic 
resonance (NMR), Raman, and Infrared (IR) spectroscopy for mole fractions of LiFSI up to $0.45 \mathrm{~mol} \mathrm{~mol}^{-1}$. All methods give evidence for the complexation of $\mathrm{Li}^{+}$with VN. The Raman spectra are most suited for quantification of this complex formation. Results from this method show that at low LiFSI concentrations four VN molecules bind to the $\mathrm{Li}^{+}$-ion. The average coordination number decreases as the LiFSI concentration increases and is only about 1 at the highest studied LiFSI concentrations. A chemical model was developed that describes the complexation quantitatively. It accounts for four complexes of the type $\left[\mathrm{Li}(\mathrm{VN})_{n}\right]^{+}$with $n=1, \ldots, 4$. The corresponding equilibrium constants are reported. The complexation of $\mathrm{Li}^{+}$with $\mathrm{VN}$ is important for all physico-chemical properties of the studied solutions and can now be described quantitatively. The study could be a blueprint for obtaining similar information on the complexation of other nitriles with $\mathrm{Li}^{+}$. Data on such systems is needed for the design of lithium-ion batteries. 


\section{Appendix A. NMR spectroscopy}

Section Appendix A gives supporting information on the NMR spectroscopic measurements. Tables A.1 to A.3 contain the numerical experimental data of the chemical shifts of the individual solvent and ion nuclei in solutions of LiFSI in VN for ${ }^{1} \mathrm{H}-,{ }^{7} \mathrm{Li}-,{ }^{13} \mathrm{C}$-, and ${ }^{19} \mathrm{~F}-\mathrm{NMR}$ as a function of the mole fraction of LiFSI at $298 \mathrm{~K}$ and ambient pressure. Figure A.1 gives an overview of the ${ }^{1} \mathrm{H}-,{ }^{7} \mathrm{Li}-,{ }^{13} \mathrm{C}-$, and ${ }^{19} \mathrm{~F}-\mathrm{NMR}$ spectra of a solution of LiFSI in VN with a mole fraction of LiFSI of $0.0331 \mathrm{~mol} \mathrm{~mol}^{-1}$ at $298 \mathrm{~K}$ and ambient pressure. 
Table A.1: Experimental data of the chemical shifts of the methylene groups (Peaks 1, 2, and 3) and methyl group (Peak 4) in the ${ }^{1} \mathrm{H}-\mathrm{NMR}$ spectraof solutions of LiFSI in VN at $298 \mathrm{~K}$.

\begin{tabular}{ccccc}
\hline \hline \multicolumn{5}{c}{${ }^{1} \mathrm{H}-\mathrm{NMR}$} \\
$x_{\text {LiFSI }}$ & Peak 1 & Peak 2 & Peak 3 & Peak 4 \\
\hline$/ \mathrm{mol} \mathrm{mol}^{-1}$ & $/ \mathrm{ppm}$ & $\delta$ & $\delta$ & $\delta$ \\
\hline 0.0000 & 1.895 & 1.139 & 1.007 & 0.491 \\
0.0331 & 1.885 & 1.114 & 0.977 & 0.461 \\
0.0667 & 1.887 & 1.099 & 0.957 & 0.442 \\
0.1219 & 1.880 & 1.073 & 0.922 & 0.406 \\
0.2019 & 1.862 & 1.038 & 0.878 & 0.358 \\
0.2557 & 1.849 & 1.022 & 0.858 & 0.336 \\
0.3347 & 1.810 & 0.987 & 0.819 & 0.295 \\
0.3980 & 1.788 & 0.970 & 0.801 & 0.276 \\
0.4422 & 1.752 & 0.937 & 0.767 & 0.242 \\
\hline$u\left(x_{\text {LiFsI }}\right)=0.0002 \mathrm{~mol} \mathrm{~mol}^{-1}, u(\delta)=0.001 \mathrm{ppm}$ \\
\hline \hline
\end{tabular}


Table A.2: Experimental data of the chemical shifts of the carbon nuclei of the nitrile group (Peak 1), the methylene groups (Peaks 2, 3, and 4) and methyl group (Peak 5) in the ${ }^{13} \mathrm{C}-\mathrm{NMR}$ spectra of solutions of LiFSI in VN at $298 \mathrm{~K}$.

\begin{tabular}{cccccc}
\hline \hline \multicolumn{5}{c}{${ }^{13} \mathrm{C}-\mathrm{NMR}$} \\
$x_{\text {LiFSI }}$ & $\delta$ & $\delta$ & $\delta$ & $\delta$ & $\delta$ \\
$/ \mathrm{mol} \mathrm{mol}^{-1}$ & $/ \mathrm{ppm}$ & $/ \mathrm{ppm}$ & $/ \mathrm{ppm}$ & $/ \mathrm{ppm}$ & $/ \mathrm{ppm}$ \\
\hline 0.0000 & 119.090 & 26.902 & 21.190 & 15.829 & 12.355 \\
0.0331 & 119.274 & 26.785 & 21.140 & 15.749 & 12.324 \\
0.0667 & 119.447 & 26.679 & 21.104 & 15.683 & 12.300 \\
0.1219 & 119.690 & 26.503 & 21.040 & 15.572 & 12.245 \\
0.2019 & 119.946 & 26.260 & 20.942 & 15.417 & 12.142 \\
0.2557 & 120.046 & 26.119 & 20.877 & 15.331 & 12.066 \\
0.3347 & 120.107 & 25.958 & 20.791 & 15.236 & 11.949 \\
0.3980 & 120.120 & 25.871 & 20.740 & 15.186 & 11.869 \\
0.4422 & 120.098 & 25.798 & 20.685 & 15.132 & 11.794 \\
\hline$u\left(x_{\text {LiFSI }}\right)=0.0002 \mathrm{~mol} \mathrm{~mol}^{-1}, u(\delta)=0.001 \mathrm{ppm}$ & \\
\hline \hline
\end{tabular}


Table A.3: Experimental data of the chemical shifts of the $\mathrm{Li}^{+}$-ion and the $\mathrm{FSI}^{-}$-ion in the ${ }^{7} \mathrm{Li}-\mathrm{NMR}$ and ${ }^{19} \mathrm{~F}-\mathrm{NMR}$ spectra, respectively, of solutions of LiFSI in VN at $298 \mathrm{~K}$.

\begin{tabular}{ccc}
\hline \hline & ${ }^{7} \mathrm{Li}-\mathrm{NMR}$ & ${ }^{19} \mathrm{~F}-\mathrm{NMR}$ \\
\hline$x_{\text {LiFSI }}$ & Peak 1 & Peak 1 \\
$/ \mathrm{mol} \mathrm{mol}^{-1}$ & $/ \mathrm{ppm}$ & $/ \mathrm{ppm}$ \\
\hline 0.0000 & - & - \\
0.0331 & -2.945 & 51.044 \\
0.0667 & -2.938 & 51.059 \\
0.1219 & -2.900 & 51.083 \\
0.2019 & -2.797 & 51.134 \\
0.2557 & -2.705 & 51.185 \\
0.3347 & -2.570 & 51.224 \\
0.3980 & -2.495 & 51.209 \\
0.4325 & - & 51.172 \\
0.4422 & -2.473 & 51.158 \\
\hline$u\left(x_{\text {LiFSI }}\right)=0.0002 \mathrm{~mol} \mathrm{~mol}^{-1}, u(\delta)=0.001 \mathrm{ppm}$ \\
\hline \hline
\end{tabular}




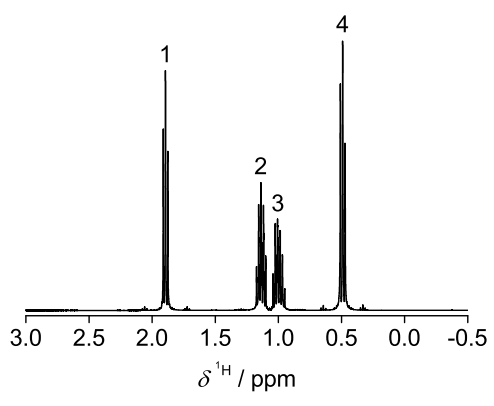

(a)

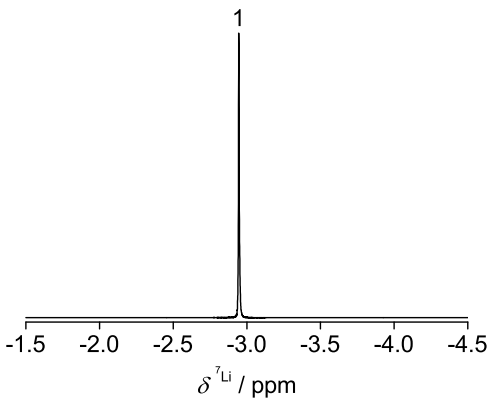

(c)

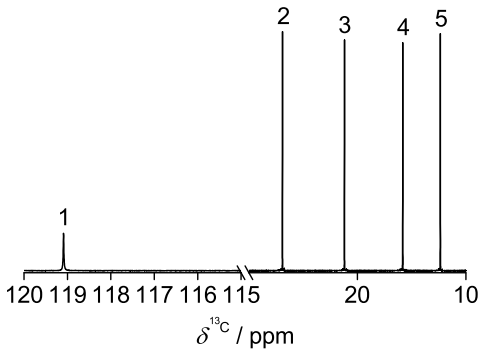

(b)

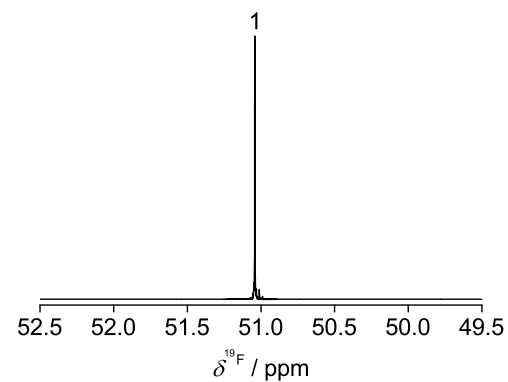

(d)

Figure A.1: NMR spectra of solutions of LiFSI in VN with a mole fraction of LiFSI of $0.0331 \mathrm{~mol} \mathrm{~mol}^{-1}$ taken at $298 \mathrm{~K}$. Panels a) and b): ${ }^{1} \mathrm{H}$ - and ${ }^{13} \mathrm{C}-\mathrm{NMR}$ spectra of the VN nuclei. Panels c) and d): ${ }^{7} \mathrm{Li}$ - and ${ }^{19} \mathrm{~F}-\mathrm{NMR}$ spectra of $\mathrm{Li}^{+}$-ion and $\mathrm{FSI}^{-}$-ion nuclei, respectively. The numbers are corresponding to the nuclei indicated in Fig. (1) in the main document. 


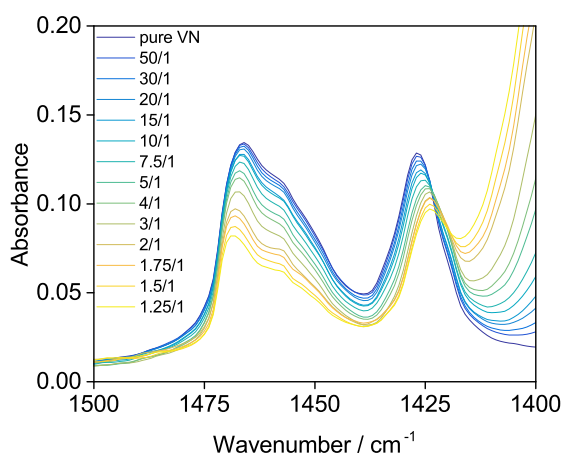

(a)

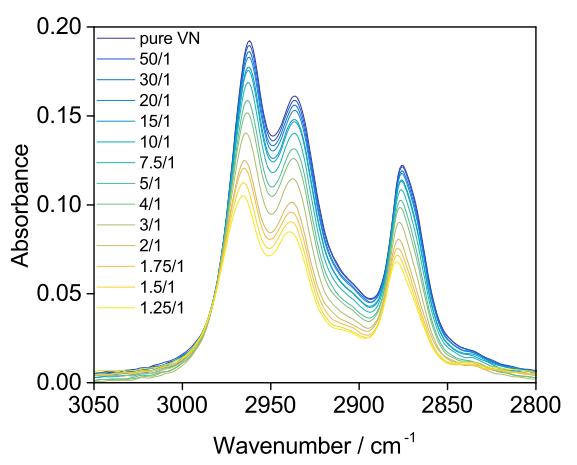

(b)

Figure B.2: IR spectra of solutions of LiFSI in VN at room temperature. Results for different molar ratios of VN / LiFSI. Different spectral regions are depicted in the two panels and can be assigned to different stretching vibrational modes: Panel a: $\mathrm{C}-\mathrm{C}$, and Panel b: $\mathrm{C}-\mathrm{H}$.

\section{Appendix B. IR spectroscopy}

Section Appendix B gives supporting information on the IR spectroscopic measurements. Figure B.2 gives an overview of the IR spectra of solutions of LiFSI in VN at $298 \mathrm{~K}$ with different spectral regions that depict different stretching vibrational modes: Panel a): $\mathrm{C}-\mathrm{C}$, and Panel b): $\mathrm{C}-\mathrm{H}$. Results for different molar ratios of VN / LiFSI. Figure B.2 gives an overview of the IR spectra of solutions of LiFSI in VN at $298 \mathrm{~K}$ with different spectral regions that depict different stretching vibrational modes of the $\mathrm{FSI}^{-}$-ion. Results for different molar ratios of VN / LiFSI. 


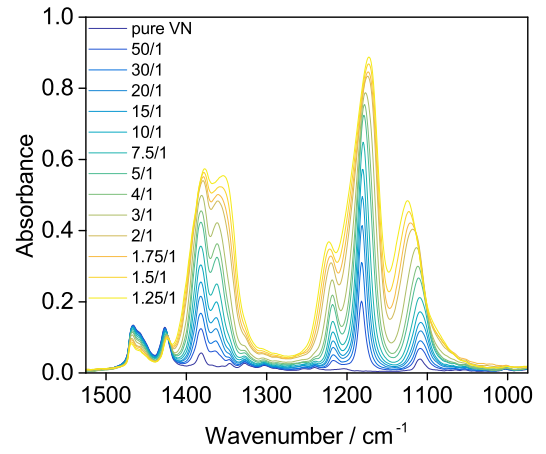

(a)

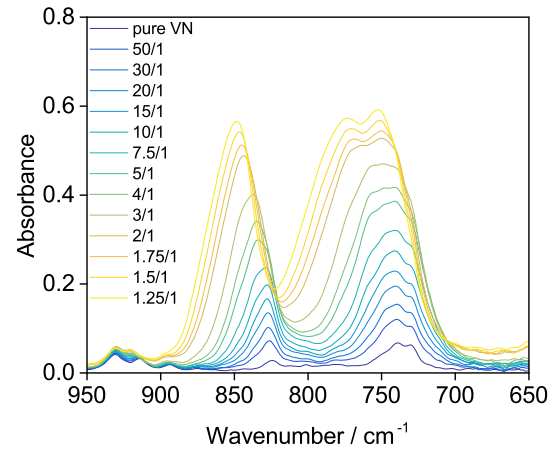

(b)

Figure B.3: IR spectra of solutions of LiFSI in VN at rom temperature. Results for different molar ratios of VN / LiFSI. Different spectral regions are depicted in the two panels and can be assigned to different stretching vibrational modes of the $\mathrm{FSI}^{-}$-ion. 


\section{Appendix C. Raman spectroscopy}

Section Appendix C gives supporting information on the Raman spectroscopic measurements. Table C.4 contains the numerical experimental data of the of the normalized integrated Raman intensities $I$ of the bands resulting from the streching of the nitrile group $(\mathrm{C} \equiv \mathrm{N})$. Figure C.4 gives an overview of the Raman spectra of solutions of LiFSI in VN at $298 \mathrm{~K}$ that depict different stretching vibrational modes of the $\mathrm{C}-\mathrm{H}$ bonds as a function of the molar ratio $\mathrm{VN} / \mathrm{LiFSI}$. 
Table C.4: Results from the Raman spectroscopic investigation of solutions of LiFSI in VN at room temperature. Experimental data of the normalized integrated Raman intensities $I$ of the bands resulting from the streching of the nitrile group $(\mathrm{C} \equiv \mathrm{N})$. The bands are labeled as shown in Figure 3 of the main document: F free VN, B1, B2: VN bound in complexes.

\begin{tabular}{cccc}
\hline \hline$x_{\mathrm{LiFSI}} / \mathrm{mol} \mathrm{mol}^{-1}$ & $I_{\mathrm{F}}$ & $I_{\mathrm{B} 1}$ & $I_{\mathrm{B} 2}$ \\
\hline 0.0000 & 12.16 & 0.00 & 0.00 \\
0.0189 & 11.50 & 0.62 & 0.16 \\
0.0331 & 10.80 & 1.21 & 0.36 \\
0.0505 & 10.04 & 1.92 & 0.58 \\
0.0667 & 9.29 & 2.60 & 0.80 \\
0.0914 & 8.17 & 3.58 & 1.12 \\
0.1219 & 6.86 & 4.71 & 1.49 \\
0.1706 & 4.82 & 6.20 & 2.43 \\
0.2019 & 3.70 & 6.97 & 3.03 \\
0.2557 & 2.10 & 7.66 & 4.26 \\
0.3347 & 0.66 & 7.45 & 6.34 \\
0.3980 & 0.39 & 6.58 & 8.10 \\
0.4422 & 0.15 & 5.94 & 9.30 \\
\hline$u\left(x_{\mathrm{LiFSI}}\right)=0.0002 \mathrm{~mol} \mathrm{~mol}$ & & \\
\hline \hline
\end{tabular}




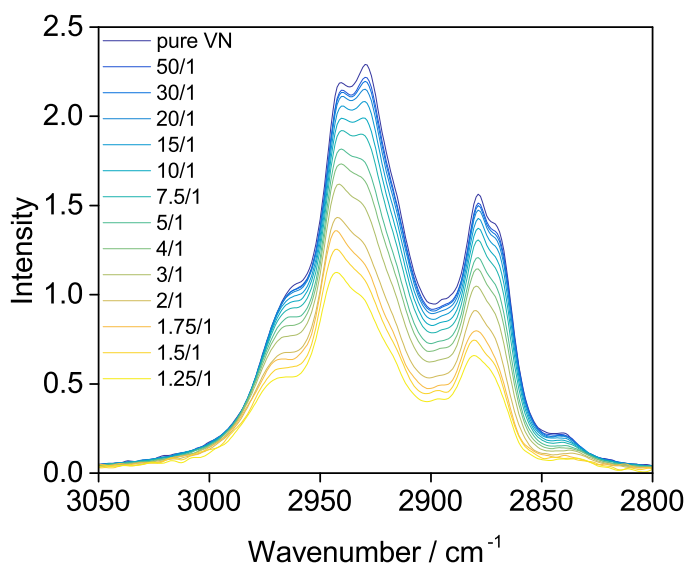

Figure C.4: Raman spectra of solutions of LiFSI in VN at $298 \mathrm{~K}$ that depict different stretching vibrational modes of the $\mathrm{C}-\mathrm{H}$ bonds as a function of the molar ratio VN / LiFSI. 


\section{References}

[1] J. Neuhaus, E. von Harbou, H. Hasse, Physico-chemical properties of solutions of lithium bis(fluorosulfonyl)imide (LiFSI) in dimethyl carbonate, ethylene carbonate, and propylene carbonate, J. Power Sources 394 (2018) 148-159. doi:10.1016/j.jpowsour.2018.05.038.

[2] H.-B. Han, S.-S. Zhou, D.-J. Zhang, S.-W. Feng, L.-F. Li, K. Liu, W.-F. Feng, J. Nie, H. Li, X.-J. Huang, M. Armand, Z.-B. Zhou, Lithium bis(fluorosulfonyl)imide (LiFSI) as conducting salt for nonaqueous liquid electrolytes for lithium-ion batteries: Physicochemical and electrochemical properties, J. Power Sources 196 (2011) 3623-3632. doi:10.1016/j.jpowsour.2010.12.040.

[3] S.-D. Han, O. Borodin, D. M. Seo, Z.-B. Zhou, W. A. Henderson, Electrolyte solvation and ionic association V. Acetonitrile-lithium bis (fluorosulfonyl) imide (LiFSI) mixtures, J. Electrochem. Soc. 161 (14) (2014) A2042-A2053.

[4] S. Lux, I. Lucas, E. Pollak, S. Passerini, M. Winter, R. Kostecki, The mechanism of $\mathrm{HF}$ formation in $\mathrm{LiPF}_{6}$ based organic carbonate electrolytes, Electrochem. Commun. 14 (2012) 47-50. doi:10.1016/j.elecom.2011.10.026.

[5] G. G. Eshetu, S. Grugeon, G. Gachot, D. Mathiron, M. Armand, S. Laruelle, LiFSI vs. $\mathrm{LiPF}_{6}$ electrolytes in contact with lithiated graphite: Comparing thermal stabilities and identification of spe- 
cific SEI-reinforcing additives, Electrochim. Acta 102 (2013) 133-141. doi:10.1016/j.electacta.2013.03.171.

[6] C. Forestier, S. Grugeon, C. Davoisne, A. Lecocq, G. Marlair, M. Armand, L. Sannier, S. Laruelle, Graphite electrode thermal behavior and solid electrolyte interphase investigations: Role of state-of-the-art binders, carbonate additives and lithium bis(fluorosulfonyl)imide salt, J. Power Sources 330 (2016) 186-194. doi:10.1016/j.jpowsour.2016.09.005.

[7] J. Wang, Y. Yamada, K. Sodeyama, C. H. Chiang, Y. Tateyama, A. Yamada, Superconcentrated electrolytes for a high-voltage lithium-ion battery, Nat. Commun. 12032 (2016) 1-9. doi:10.1038/ncomms12032.

[8] J. Neuhaus, D. Bellaire, M. Kohns, E. von Harbou, H. Hasse, Selfdiffusion coefficients in solutions of lithium bis(fluorosulfonyl)imide with dimethyl carbonate and ethylene carbonate, Chem. Ing. Tech. 91 (11) (2019) 1633-1639. doi:10.1002/cite.201900040.

[9] D. M. Seo, O. Borodin, S.-D. Han, Q. Ly, P. D. Boyle, W. A. Henderson, Electrolyte Solvation and Ionic Association, J. Electrochem. Soc. 159 (5) (2012) A553-A565. doi:10.1149/2.jes112264.

[10] D. M. Seo, O. Borodin, S.-D. Han, P. D. Boyle, W. A. Henderson, Electrolyte Solvation and Ionic Association II. Acetonitrile-Lithium Salt Mixtures: Highly Dissociated Salts, J. Electrochem. Soc. 159 (9) (2012) A1489-A1500. doi:10.1149/2.035209jes. 
[11] S.-D. Han, O. Borodin, J. L. Allen, D. M. Seo, D. W. McOwen, S.H. Yun, W. A. Henderson, Electrolyte solvation and ionic association IV. Acetonitrile-lithium difluoro (oxalato) borate (LiDFOB) mixtures, J. Electrochem. Soc. 160 (11) (2013) A2100-A2110.

[12] H. Duncan, N. Salem, Y. Abu-Lebdeh, Electrolyte formulations based on dinitrile solvents for high voltage Li-ion batteries, J. Electrochem. Soc. 160 (6) (2013) A838-A848.

[13] Y.-S. Kim, T.-H. Kim, H. Lee, H.-K. Song, Electronegativity-induced enhancement of thermal stability by succinonitrile as an additive for Li ion batteries, Energy Environ. Sci. 4 (10) (2011) 4038-4045. doi:10.1039/C1EE01272J.

[14] M. Nagahama, N. Hasegawa, S. Okada, High voltage performances of Li2nipo4f cathode with dinitrile-based electrolytes, J. Electrochem. Soc. 157 (6) (2010) A748-A752.

[15] Y. Abu-Lebdeh, I. Davidson, New electrolytes based on glutaronitrile for high energy/power Li-ion batteries, J. Power Sources 189 (1) (2009) 576-579. doi:10.1016/j.jpowsour.2008.09.113.

[16] Y. Abu-Lebdeh, I. Davidson, High-Voltage Electrolytes Based on Adiponitrile for Li-Ion Batteries, J. Electrochem. Soc. 156 (1) (2009) A60. doi:10.1149/1.3023084.

[17] J. Neuhaus, E. von Harbou, H. Hasse, Physico-chemical Properties of LiFSI Solutions I. LiFSI with Valeronitrile, Dichloromethane, 1,2- 
Dichloroethane, and 1,2-Dichlorobenzene, J. Chem. Eng. Data 64 (3) (2019) 868-877. doi:10.1021/acs.jced.8b00590.

[18] J. Barthel, R. Deser, FTIR study of ion solvation and ion-pair formation in alkaline and alkaline earth metal salt solutions in acetonitrile, J. Solution Chem. 23 (10) (1994) 1133-1146.

[19] D. M. Seo, O. Borodin, D. Balogh, M. O'Connell, Q. Ly, S.-D. Han, S. Passerini, W. A. Henderson, Electrolyte solvation and ionic association III. Acetonitrile-lithium salt mixtures-transport properties, J. Electrochem. Soc. 160 (8) (2013) A1061-A1070.

[20] W. Ronaldá Fawcett, Attenuated total reflection fourier-transform infrared spectroscopic study of ion-solvent and ion-ion interactions in alkali-metal perchlorate-acetonitrile solutions, J. Chem. Soc., Faraday Trans. 89 (5) (1993) 811-816.

[21] J.-S. Seo, B.-S. Cheong, H.-G. Cho, Solvation of LiClO4 and NaClO4 in deuterated acetonitrile studied by means of infrared and Raman spectroscopy, Spectrochim. Acta, Part A 58 (8) (2002) 1747-1756. doi:10.1016/S1386-1425(01)00636-9.

[22] J. M. Alía, H. G. M. Edwards, J. Moore, Solvation of Ag+ ions in some nitriles; a Fourier transform Raman spectroscopic study, Spectrochim. Acta, Part A 51 (12) (1995) 2039-2056. doi:10.1016/0584-8539(95)01454-1.

[23] B. G. Oliver, G. J. Janz, Raman spectra of silver nitrate in water- 
acetonitrile mixtures, J. Phys. Chem. 74 (21) (1970) 3819-3822. doi:10.1021/j100715a017.

[24] C. R. Witschonke, Freezing point and purity data for some organic compounds, Anal. Chem. 26 (3) (1954) 562-564.

[25] R. R. Dreisbach, S. A. Shrader, Vapor pressure-temperature data on some organic compounds, Ind. Eng. Chem. 41 (12) (1949) 2879-2880.

[26] F. E. Condo, E. T. Hinkel, A. Fassero, R. L. Shriner, Identification of Nitriles. II. Addition Compounds of Nitriles with Mercaptoacetic Acid, J. Am. Chem. Soc. 59 (2) (1937) 230-232. doi:10.1021/ja01281a003.

[27] S. Dernini, A. M. Polcaro, B. Marongiu, S. Porcedda, Excess volumes and gibbs free energies of mixtures containing alkanenitriles, Fluid Phase Equilib. 87 (1) (1993) 163-175. doi:10.1016/0378-3812(93)85024-G.

[28] R. Eustaquio-Rincón, A. Trejo, Thermodynamics of liquid binary (alkanenitrile-alkane) mixtures. Part1.-Experimental excess molar volume at $298.15 \mathrm{~K}$ and its interpretation with the Prigogine-Flory-Patterson theory, J. Chem. Soc., Faraday Trans. 90 (1) (1994) 113-120. doi:10.1039/FT9949000113.

[29] G. Marras, S. T. Blanco, S. Otín, Excess molar volumes of nitrile + ketone mixtures at 298.15 K, Thermochim. Acta 242 (1994) 27-32. doi:10.1016/0040-6031(94)85005-4.

[30] J. J. Banewicz, J. A. Maguire, P. S. Shih, Electrical conductance of tetraethylammonium perchlorate in valeronitrile, J. Phys. Chem. 72 (6) (1968) 1960-1963. 
[31] J. M. Dereppe, M. van Meerssche, Moment Dipolaire de Nitriles Aliphatiques, Bull. Soc. Chim. Belg. 69 (9-10) (1960) 466-474. doi:10.1002/bscb.19600690904.

[32] P. M. Claudeammann, E. Andre, A simple multinuclear NMR thermometer, J. Magn. Reson. 46 (1982) 319-321.

[33] K. Fujii, S. Seki, S. Fukuda, R. Kanzaki, T. Takamuku, Y. Umebayashi, S.-i. Ishiguro, Anion Conformation of Low-Viscosity Room-Temperature Ionic Liquid 1-Ethyl-3-methylimidazolium Bis(fluorosulfonyl) Imide, J. Phys. Chem. B 111 (44) (2007) 12829-12833. doi:10.1021/jp074325e.

[34] S. Gatto, O. Palumbo, S. Caramazza, F. Trequattrini, P. Postorino, G. B. Appetecchi, A. Paolone, The infrared spectrum of bis(fluorosulfonyl)imide revisited: Attractive performances of the PBE0/6-31g** model, Vib. Spectrosc. 82 (2016) 16-21. doi:10.1016/j.vibspec.2015.11.005.

[35] K. Matsumoto, T. Oka, T. Nohira, R. Hagiwara, Polymorphism of Alkali Bis(fluorosulfonyl)amides $\left(\mathrm{M}\left[\mathrm{N}\left(\mathrm{SO}_{2} \mathrm{~F}\right)_{2}\right], \mathrm{M}=\mathrm{Na}, \mathrm{K}\right.$, and $\left.\mathrm{Cs}\right)$, Inorg. Chem. 52 (2) (2013) 568-576. doi:10.1021/ic3010486.

[36] A. Vij, R. L. Kirchmeier, J. M. Shreeve, R. D. Verma, Some fluorinecontaining nitrogen acids and their derivatives, Coord. Chem. Rev. 158 (1997) 413-432. doi:10.1016/S0010-8545(97)90069-2.

[37] P. Neelakantan, Raman spectrum of acetonitrile, Proc. - Indian Acad. Sci., Sect. A 60 (6) (1964) 422-424. doi:10.1007/BF03047422. 
[38] R. E. Kitson, N. E. Griffith, Infrared absorption band due to nitrile stretching vibration, Anal. Chem. 24 (2) (1952) 334-337.

[39] G. A. Crowder, Vibrational assignment for propionitrile, Spectrochim. Acta, Part A 42 (10) (1986) 1229-1231. doi:10.1016/0584-8539(86)80080-0.

[40] Z. Deng, D. E. Irish, A Raman spectral study of solvation and ion association in the systems LiAsF6/CH3co2ch3 and LiAsF6/HCO2ch3, Can. J. Chem. 69 (11) (1991) 1766-1773.

[41] I. Z. Korostyshevskii, M. M. Aleksankin, L. I. Fileleeva, V. N. Koval'chuk, The principles of field dissociation of nitriles, Theor. Exp. Chem. 8 (6) (1974) 640-645.

[42] H. Schmidt, A. Schweig, Semiquantitative Proof of Hyperconjugation, Angew. Chem., Int. Ed. Engl. 12 (4) (1973) 307-308. doi:10.1002/anie.197303071.

[43] R. G. Lerner, B. P. Dailey, Microwave Spectrum and Structure of Propionitrile, J. Chem. Phys. 26 (3) (1957) 678-680. doi:10.1063/1.1743366.

[44] E. C. Hurdis, C. P. Smyth, The Structural Effects of Unsaturation and Hyperconjugation in Aldehydes, Nitriles and Chlorides as Shown by their Dipole Moments in the Vapor State, J. Am. Chem. Soc. 65 (1) (1943) 89-96. 
[45] J. Barthel, R. Buchner, E. Wismeth, FTIR spectroscopy of ion solvation of $\mathrm{LiClO} 4$ and $\mathrm{LiSCN}$ in acetonitrile, benzonitrile, and propylene carbonate, J. Solution Chem. 29 (10) (2000) 937-954. 